\title{
Re-Purposing Evodiamine as an Anti-Cancer Drug: Effects on Migration and Apoptosis
}

\author{
Tomas Koltai* \\ Independent researcher, Italy \\ Received: 眥 March 27, 2018; Published: 眥 April 05, 2018 \\ *Corresponding author: Tomas Koltai, Independent researcher, Florence, Italy
}

\section{Abstract}

Introduction: Evodiamine is a quinolone alkaloid compound obtained from a fruit described in traditional Chinese medicine. It has been in use for many centuries for the treatment of headaches, menstrual problems, abdominal pain and other ailments. In the western world, it is known as a controversial weight loss product and is sold over the counter as a nutritional supplement. Many freely sold weight loss products contain evodiamine associated with other supposed weight control chemicals. Even though there are no reliable statistics, we may presume that thousands of persons have been using it without serious side effects being reported.

Background: At the beginning of this century researchers found that this compound had anti-cancer effects: cytotoxicity and decreased invasion and migration in vitro in malignant cells while showing minimal damage to normal cells. Little has been investigated about in vivo effects on cancer. There is a lack of information regarding the possibility of achieving the clinical concentrations needed for tumour cytotoxicity and for inhibiting migration.

Objectives: The goal of this study was to determine the feasibility of re-purposing evodiamine as an anti-cancer drug. For this, we investigated:

a. the possibility of achieving the cytotoxic concentrations of the drug required at tumor level in the clinical setting;

b. the molecular mechanisms responsible for the anti-cancer effects;

c. which types of tumours can be treated;

d. its interrelation with other chemotherapeutics;

e. Interrelation of evodiamine with berberine in anti-cancer effects.

Material and Methods: Due to the abundance of published research on evodiamine, many of the objectives could be accomplished by reviewing the literature, introducing a systematic search, and organizing the findings.

Results: The necessary concentrations to achieve possible clinical results may be reached through oral administration. This concept applies mainly to inhibition of migration, that requires a low concentration. The cytotoxic effects need higher concentrations that are not easily attainable with standard preparations. An association with berberine, a non-toxic compound, increases evodiamine's cytotoxicity. Almost all malignancies, whether solid or hematologic, are affected by evodiamine in a dose dependent manner. Evodiamine may also complement the activity of other chemotherapeutics like campthotecin, taxanes, doxoubicin and probably radiotherapy as well.

Conclusion: Evodiamine should be tested in humans to establish the achievable plasma concentrations, because all the published pharmacodynamic reports were based on tests on rodents. Whether alone or associated with berberine, evodiamine,deserves to be tested in well designed clinical trials for the treatment of cancer and prevention of metastasis.

Keywords: Evodiamine; Cancer; Apoptosis; Migration; Metastasis; Berberine 


\section{Introduction}

The search for pharmacologically interesting drugs among traditional Chinese herbs has been the origin of a few important success stories. That is the case, for example, of artemisinin and its derivatives in the treatment of malaria. This drug has proven to be the most important innovation in malaria treatment in the last fifty years. However, there are other interesting molecules among Chinese herbs that did not achieve the same success and in a certain way; they have been neglected in terms of research and development. Evodiamine (EVO) is one of those drugs. EVO is a natural compound, a quinolone alkaloid isolated from the fruit of Evodia rutaecarpa (Wu-Chu-Yu is the Chinese name). In China, the dried unripe fruits of Evodia rutaecarpa have been traditionally used for the treatment of a variety of symptoms like abdominal pain, headache, menstrual disturbances and postpartum haemorrhage [1]. In the west, EVO obtained from this fruit has been used as a weight loss dietary supplement (under the brand name of Evodia and others), in spite of the fact that its weight loss properties have never been scientifically demonstrated and are still controversial.

Table 1: Pharmacological activities of EVO other than anti-cancer effects.

\begin{tabular}{|c|c|}
\hline Action & Reference \\
\hline Stimulation of cathecolamine secretion & [2] \\
\hline Pain relief & [3] \\
\hline Anti-inflammatory & {$[4,5]$} \\
\hline Weight loss through increased thermogenesis (weight loss with EVO is a controversial issue which has not been fully clarified) & [6-8] \\
\hline Vasodilation & [9] \\
\hline Inhibitory effects on the synthesis of prostaglandin E2 (PGE2), this can be considered as part of its anti-inflamatory effects. & [10] \\
\hline Increased insulin sensitivity & [11] \\
\hline Increase secretion of testosterone by the testicle & [12] \\
\hline Ureterotonic effect & [13] \\
\hline Diuretic effect through the inhibition of aldosterone release & [14] \\
\hline Protection of myocardial muscle in the ischemia-reperfusion process & [15] \\
\hline
\end{tabular}

In the last fifteen years there has been growing evidence that EVO exerts anti-cancer activity. EVO has different pharmacological actions that are summarized in Table 1 (which shows the wide spectrum of diverse effects of this compound), but we are only considering in depth those related to anti-cancer effects. The important fact is that it has been tested in humans as a dietary supplement and no important adverse effects were found [2], however, it was mixed with other weight loss products and dose has not been clearly established. In other human experiments of the same kind, it was used at a dose of $500 \mathrm{mg}$ in one intake [3]. An ANSES (French Agency for Food, Environmental and Occupational Health \& Safety) publication [4] analyzing the risks and adverse events of food supplements stated that: "The adverse effects of evodiamine may be related to its ability to activate the capsaicin receptor underlying its positive inotropic and chronotropic actions $[5,6]$ and vasodilator actions (risk of hypotension) (Kobayashi et al. 2000)".

Another paragraph on the issue ANSES says: "The major alkaloids of Evodia, evodiamine and rutaecarpine, have modulatory effects on metabolizing enzymes, in particular cytochromes P450 CYP3A4, CYP1A2 and CYP1A1 (Ueng et al. 2002; Wen et al. 2014) [7] which metabolize many drugs". No other major adverse effects are described in this "opinion" of ANSES, and no other warnings are given. At this point, we may assume that the main adverse effects and tolerable doses are known. Furthermore, it is an over the counter drug that is probably widely used for its (real or fake) weight loss effect.

\section{EVO`s effects related to anti-cancer activity}

EVO has shown inhibitory effects on migration of MDA-MB-231 breast cancer cells with a significant reduction of lung metastasis. It also induced cancer cell apoptosis through caspase activation. EVOtreated xenografted mice with MDA-MB-231 showed a reduction of nearly $50 \%$ in lung metastasis when compared with the control group $[8,9]$. EVO also exhibited an important cytotoxic activity against other tumors like colon and hepatoma human cell lines $[10,11]$. Table 2 shows different malignant cell lines where EVO has anti-cancer effects. In spite of the evidence of a cytotoxic activity of EVO on different lines of cancer cells, EVO did not show toxicity against normal cells [12].

Table 2.

\begin{tabular}{|c|c|}
\hline Tumour & References \\
\hline Breast & {$[19-26]$} \\
\hline Colorectal & {$[27,28]$} \\
\hline Gastric & {$[29-33]$} \\
\hline Liver & {$[34,35]$} \\
\hline Pancreas & {$[36]$} \\
\hline Thyroid & {$[37]$} \\
\hline Non small-cell lung cancer & {$[38,39]$} \\
\hline Small-cell lung cancer & {$[40]$} \\
\hline Prostate & {$[41-43]$} \\
\hline Bladder & {$[44]$} \\
\hline Leukemia & {$[45]$} \\
\hline
\end{tabular}




\begin{tabular}{|c|c|}
\hline Melanoma & {$[46]$} \\
\hline Nasopharyngeal carcinoma & {$[47]$} \\
\hline Renal carcinoma cells & {$[48,49]$} \\
\hline Urothelial cell carcinoma & {$[50]$} \\
\hline Glioblastoma & {$[51]$} \\
\hline Ovarian & {$[52-54]$} \\
\hline Osteosarcoma & {$[55,56]$} \\
\hline Oral cancer cells & {$[57]$} \\
\hline Cervical cancer (HeLa) & {$[58]$} \\
\hline
\end{tabular}

\section{EVO`s mechanisms of action on malignant cells}

The evidence outlined above clearly shows that EVO acts as a cytotoxic agent for malignant cells without affecting the normal cells (or affecting them minimally). It is necessary now to describe the mechanisms involved in the anti-cancer activity.

\section{Apoptosis}

The experimental research shows that EVO is an apoptotic inducer of malignant cells. In the case of HeLa cervical cancer the mechanism described is caspase dependent because it can be eliminated with caspase inhibitors. The caspase dependent apoptosis in HeLa also showed increased expression of Bax and decreased expression of Bcl-2 which means an alteration of the Bax-Bcl-2 balance [13]. Lee et al [14] found that EVO could develop its pro-apoptotic activity through caspase dependent and caspase independent mechanisms in leukemic cells. Whether EVO's apoptotic mechanisms are cell- or tissue-dependent has not been clarified but on Table 3 we can see that apoptosis induced by EVO has been found in all the malignant cell lines tested. Table 3 lists the cells where apoptosis is one of the mechanisms of EVO's anticancer effects.

Table 3.

\begin{tabular}{|c|c|}
\hline Apoptosis has been described in: & References \\
\hline Leukemic U937 cells. & {$[45]$} \\
Leukaemia K562 cell line & {$[62,63]$} \\
Leukemic T-lymphocytes & {$[73]$} \\
Human myeloid leukaemia KBM5 & {$[74]$} \\
\hline Cervical cancer HeLa cells & {$[58,69]$} \\
\hline Breast cancer cells: MCF-7 & {$[19]$} \\
MCF-7 doxorubicin resistant & {$[25]$} \\
NCI/ADR-RES cells & {$[23]$} \\
Renal carcinoma cells: Caki-1 & {$[49]$} \\
\hline Bel-7402 hepatoma cell line & {$[59,60,64]$} \\
SMMC-7721 hepatoma line & {$[65]$} \\
\hline
\end{tabular}

\begin{tabular}{|c|c|}
\hline Urothelial cell carcinoma & {$[50]$} \\
\hline Glioblastoma: U87 and C6 cells & {$[51]$} \\
\hline Human lung cancer A549 and H1299 cells. & {$[61,38,74]$} \\
\hline Human ovarian cancer cells HO-8910PM and & {$[52]$} \\
A2780, A2780CP, ES2, SKOV-3 & {$[53]$} \\
\hline Gastric carcinoma stem cells & {$[30]$} \\
\hline Colorectal cancer cell HCT-116 & {$[65]$} \\
\hline COLO205 and HT-29 & {$[27]$} \\
\hline Gastric carcinoma cells SGC-7901 & {$[66,67]$} \\
\hline Osteosarcoma & {$[56]$} \\
\hline Human small-cell lung cancer H446 and H1688 & {$[40]$} \\
\hline Melanoma A375-S2 cells & {$[70-72]$} \\
\hline Prostate DU145 and PC3 & {$[41,43]$} \\
\hline LnCaP & {$[42]$} \\
\hline Human squamous cell carcinoma FaDu & {$[74]$} \\
\hline Jurkat human T-cell lymphoma & {$[74]$} \\
\hline Human multiple myeloma U266 & {$[74]$} \\
\hline Murine fibrosarcoma L929 & {$[77]$} \\
\hline blood cells. & {$[77]$} \\
\hline No effects on normal human peripheral mononuclear & \\
\hline
\end{tabular}

This apoptosis seems to be p53 independent and may involve both, extrinsic and intrinsic apoptotic pathways [15]. It has also apoptotic effects on cancer stem cells [16]. The mechanism of cell death is not only apoptotic, it may also be necrotic [17]. The first cytotoxic finding is apoptosis, but $15 \mathrm{micromol} / \mathrm{L}$ of EVO induced necrosis after 24 hours of incubation. As mentioned, the apoptosis may be reached by caspase dependent and caspase independent pathways, but also through Fas-L/NF-kB (76), PI3K/Akt/caspase [18], and the sphingomyelin pathway [19]. SIRT1 and protein kinase $\mathrm{C}$ inhibition may also represent another apoptotic pathway [20].

\section{Inhibition of migration, invasion and metastasis}

Migration is the first step of invasion and eventual metastasis. EVO has shown clear signs of its ability to inhibit migration and therefore reduce the number of metastases. The evidence is summarized in Table 4. Ogasawara et al. [9] attributed the antimigratory effects of EVO to the methyl group at N-14 and the hydrogen at $\mathrm{C}-13 \mathrm{~b}$. It is important to underline that migration inhibition can be achieved with low concentrations of EVO that are perfectly obtainable in the clinical setting as we shall see below. The molecular mechanism that EVO employs for inhibiting migration, even if not fully known, may be centered on the protein cortactin, considered by Maders et al. as the "master switch" of the invadopodia [21]. When cortactin is phosphorylated it polymerizes the actin fibers in the invadopodia and at the same time intervenes in extracellular matrix proteolysis by modulating metalloproteases release. These steps are a pre-requisite for migration. Even if the full process is not fully known (Figure $1 \& 2$ ). 


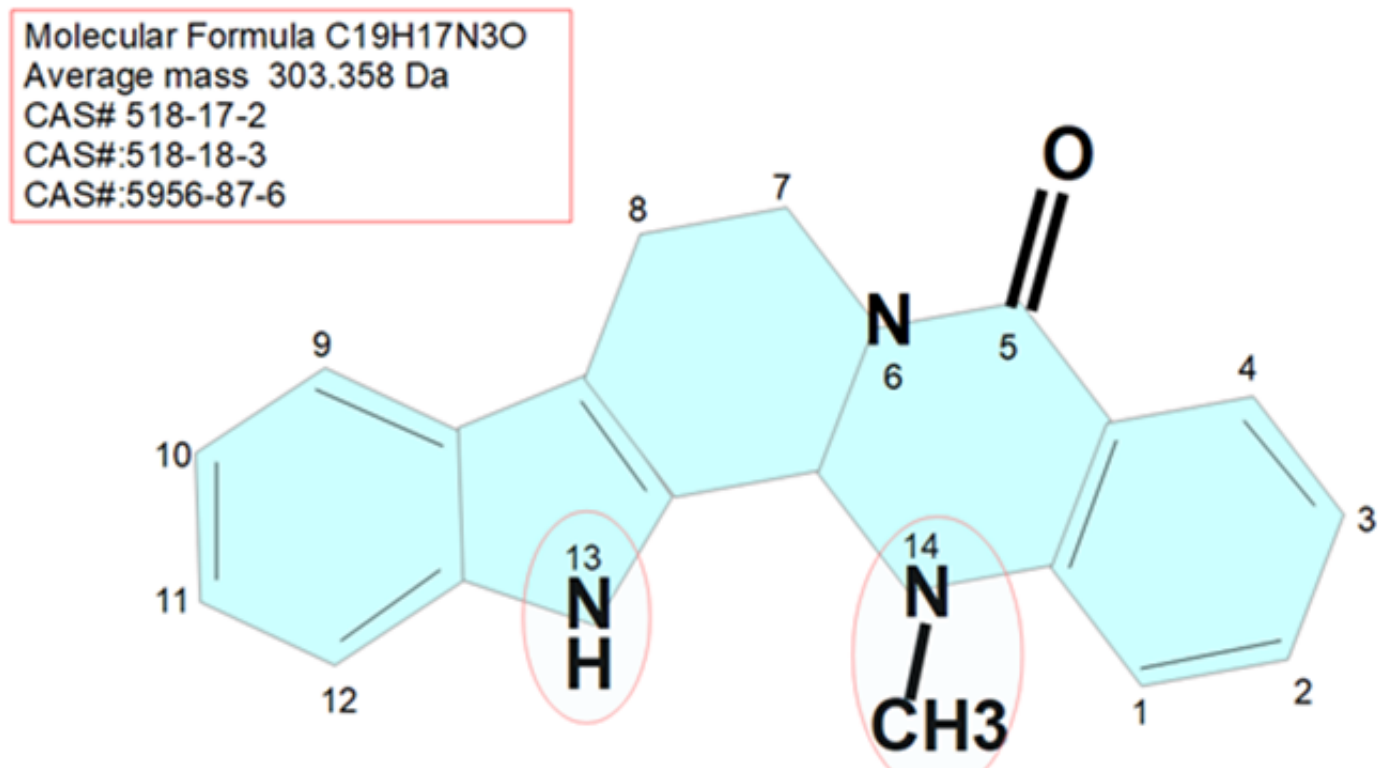

EVODIAMINE: CHEMICAL STRUCTURE

\section{Positions 13 and14 are marked because they are the usual sites where modifications are introduced to improve bioavailability, solubility and enhanced cytotoxicity.}

Figure 1: Evodiamine chemical structure. Derivatives with improved anti-cancer capacities or increased solubility, usually introduce modifications in positions 13 and 14. EVO was the first alkaloid isolated from E. rutaecarpa's fruit and is the main active principle of this plant.

Table 4.

\begin{tabular}{|c|c|}
\hline Reference & Findings \\
\hline [19] & EVO reduced metastasis in MDA-MB-231 breast cancer cells. \\
\hline$[20]$ & $\begin{array}{l}\text { EVO showed anti-invasive and anti-metastatic effects on Lewis lung carcinoma, B16-F10 melanoma and colon } 26 \text {-L5 carcinoma. } \\
\text { The experiments with 26-L5 tumor cell inoculation after incubation with EVO significantly decreased the number of liver and lung } \\
\text { metastasis. }\end{array}$ \\
\hline$[21]$ & $\begin{array}{l}\text { After examining } 75 \text { natural compounds, searching their inhibitory effect on migration and proliferation of colon cancer cells, EVO was } \\
\text { found to be the most potent and selective inhibitor of tumor cell migration. This inhibition was achieved with concentrations } 20 \text { times } \\
\text { lower than the one needed to inhibit tumor proliferation. }\end{array}$ \\
\hline$[47]$ & $\begin{array}{l}\text { EVO inhibited the migration of HOME1 and CNE1 nasopharyngeal cancer cells without affecting proliferation; it decreased MMP2 } \\
\text { expression and activity without affecting MMP9, and inhibited the translocation of NF-kB p65. The authors attributed these actions to } \\
\text { the attenuation of ERK1/2 phosphorylation. }\end{array}$ \\
\hline$[48]$ & EVO modifies the expression of many genes related to migration in renal cell carcinoma. \\
\hline$[65]$ & $\begin{array}{c}\text { EVO inactivated the JAK2/STAT3 pathway which lead to decrease in MMP3`s expression in HCT-116 human colorectal cells and } \\
\text { decreased migration. }\end{array}$ \\
\hline$[74]$ & $\begin{array}{l}\text { The authors propose the EVO modulation of NF-kB as the main mechanism for decreasing proliferation, invasion and metastatic } \\
\text { behavior. }\end{array}$ \\
\hline$[79]$ & $\begin{array}{l}\text { When HUVEC is stimulated with TGF- } \beta 1 \text { there is increased migration. EVO blocked this increase. EVO also blocked the activation of } \\
\qquad \text { Smad2, Smad3, ERK1/2, and Akt, and nuclear translocation of Smad4 in HUVEC. }\end{array}$ \\
\hline$[80]$ & $\begin{array}{l}\text { EVO decreased expression of metalloproteinases and cell adhesion molecules through activation of the expression of peroxisome } \\
\text { proliferator-activated receptor } \gamma(\operatorname{PPAR} \gamma) \text { and its translocation to the nucleus. }\end{array}$ \\
\hline$[81]$ & $\begin{array}{l}\text { The antimigratory properties of Evo in LIGHT induced migration of monocytes was attributed to a decrease in light induced production } \\
\text { of ROS, IL8, IL6, TNF alfa, monocyte chemoattractant protein-1, ICAM-1, CCR1 and CCR2. }\end{array}$ \\
\hline
\end{tabular}




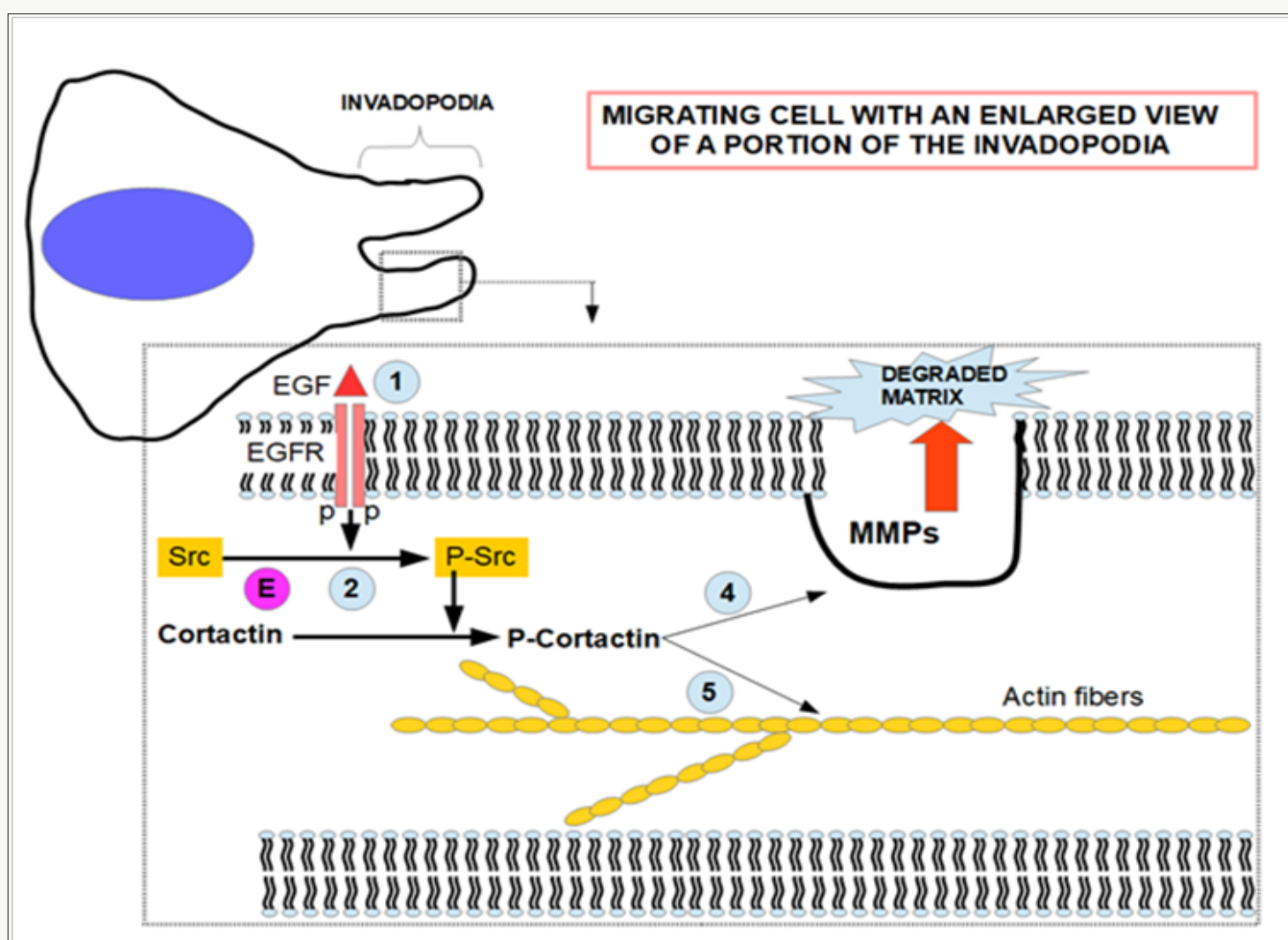

Figure 2: Proposed mechanism for EVO inhibition of migration. References 1) EGF binding and dimerization of the receptor EGFR with phosphorylation; 2) then, it phosphorylates Src; 3) Src phosphorylates cortactin that 4) modulates MMPs secretion and 5) polymeryzes actin fibers. E) site of action of EVO that inhibits Src phosphorylation. Right side of the cell represents the invadopodia. The pseudotubular aspect of invadopodia follows the description made by Brisson et al. [83] in which the extracellular matrix is entrapped in the lumen. NHE-1, VGSC channels and caveolin rafts are also essential structures of the invadopodia that were omitted for a better understanding of the drawing.

The fundamentals for the construction of Figure 2 are:

a. The pathway described by Maders [21] consisting in: EGFR-Src-Arg-cortactin. (Arg was not included in the figure for the sake of clarity. The signal starts at EGFR whether by activation of EGF or by self-activation.

b. The EGF phosphorylation of cortactin is essential for invadopodia formation and maturation [22].

c. Cells treated with either Arg or Src siRNA, showed an important reduction in proteolysis-dependent invasion [21].

d. Cortactin is an important regulator of matrix metalloproteinase secretion [23].

e. Cortactin is a key player in cell migration and invasion $[24,25]$

f. EVO has the ability to inhibit Src phosphorylation which in turn is an important factor in cortactin activation [26-28].

g. Berberinealso has the ability to reduceSrcphosphorylation [29]. This is probably the reason why it can act synergistically with EVO in reducing cell motility and invasiveness.

\section{Cell Cycle Arrest}

We shall study this effect in different tissues, because the mechanisms involved may differ according to tissues.

a. Breast Cancer: EVO decreased the expression of ER $\alpha$ and $\beta$ and mediated degradation of ER (estrogen receptors) inhibiting proliferation in MCF-7 and MDA-MB-231 breast cancer cell lines (24). In adriamycin-resistant human breast cancer NCI/ADR-RES cell lines EVO was found to increase tubulin polymerization with G2/M arrest [12].

b. Thyroid cancer: A G2/M arrest was observed when ARO cells were treated with EVO. At the same time researchers found increased expression of cdc25c and cyclin B1 and decreased expression of cdc-p15 [30].

c. Colon cancer: In lovo colon cancer cells the $S$ phase arrest was accompanied by decreased expression of cyclin A and cyclin-dependent kinase 2 and cdc25c [31]. In COLO205 and HT-29 lines the G2/M arrest was accompanied by increased expression of cdc25c and cyclin B1;c-Jun N-terminal kinase (JNK) protein phosphorylation was also increased. JNK activation is a key step for apoptosis [32]. 
d. Hepatoma: EVO inhibited STAT3 activation, JAK2, Src and ERK1/2. This was accomplished by EVO induced overexpression of shatterproof phosphatase 1 (SHP1) [28]. In SMMC-7721 hepatocarcinoma cell lines, EVO in synergy with berberine produced cell cycle arrest and apoptosis and TNF $\alpha$ was significantly increased [33]. The cell cycle arrest and posterior apoptosis produced by EVO is probably linked to increased nitric oxide (NO) production induced by this drug, interplaying with ROS. NO activates p53 and p21 and finally induce cell cycle arrest and apoptosis. This mechanism was described in melanoma and HeLa cells $[34,35]$ but probably is shared by almost all cells susceptible to EVO's action. The conclusion is that oxidative stress plays an important role in EVO`s cell cycle arrest and apoptosis.

e. Prostate cancer and urothelia: Normal prostate and particularly prostate cancer cells have increased expression of the transmembrane receptor Transient receptor potential vanilloid-1 (TRPV1) [36]. The activation of this receptor (e.g. with capsaicin) decreases the intracellular concentration of calcium. EVO is a TRPV1 agonist (similar to capsaicin regarding this action) [37]. The stimulation of TRPV1 produces a FAS dependent apoptosis in urothelial cells [38,39] and apoptosis in prostate cancer cells [40].

The possible mechanism involved in these actions of TRPV1 is through an increase in ROS [41].

TRPV2 activation also inhibits glioblastoma stem cell proliferation [42].

f. Autophagy: EVO may induce autophagy as a defense mechanism of cell survival, so that its activity in apoptosis is enhanced if it is used simultaneously with inhibitors of autophagy, otherwise EVO may protect cancer cells from apoptosis via autophagy [43].

\section{Anti-anoxia/hypoxia actions of EVO}

Hypoxia is an important component of the tumor microenvironment and there is a complex mechanism of adaptation to extreme lack of oxygen through metabolic changes initiated by HIF-1 $\alpha$ (hypoxia inducible factor- 1 alfa) and the hypoxia responsive elements. Hypoxia and HIF are strong drivers of tumor proliferation and evolution (the analysis of this fundamental issue goes beyond the scope of this article). Any therapy that decreases tumor`s hypoxia or HIF-1 $\alpha$ expression may represent a very useful complementary treatment. It has been reported that EVO had strong "anti-anoxic" effects [44]. The anti-anoxic effect of EVO is probably due to two different but complementary actions:

a. Vasodilation: EVO is a powerful vasodilator through the activation of potassium channels in the vasculature and by interference with phosphodiesterase`s degradation of cAMP and cGMP [45]. b. Decreased HIF-1 $\alpha$ by regulating its transcriptional activity through dephosphorylation of Akt [46-48].

\section{Effects on angiogenesis}

Angiogenesis is a component of tumor expansion and metastasis. In a very early phase of tumor development HIF- $1 \alpha$ upregulates the expression of vascular endothelial growth factor (VEGF) which is a driver of new vessel formation. Although these new vessels are highly incompetent from a functional point of view, they play an important role in the metastatic process. EVO has clearly shown anti-angiogenic effects [49,50].

\section{EVO and the vanilloid receptor Transient Receptor Potential Vanilloid-1 (TRPV1)}

EVO is an agonist of the vanilloid receptor TRPV1, that is a calcium ion channel activated by vanilloids, protons, heat and several inflammatory mediators. It is i in pain sensing and inflammatory processes [51] and contributes to the regulation of intracellular calcium. TRPV1 is overexpressed in different tumors including breast cancer. Activation of this receptor showed growth inhibition, induction of apoptosis and necrosis in breast cancer in general and in the most aggressive types like the triple negative [52]. The experiments were performed with capsaicin, a TRPV1 activator, but EVO is also an agonist of TRPV1 and acts in a very similar way as capsaicin, so probably the same result could probably be achieved with EVO.

\section{Summary of EVO's effects in cancer}

a. Inhibition of migration and invasion probably through Src inhibition.

b. Cell cycle inhibition in the G2/M phase by modulation of cyclins/CDKs

c. Apoptosis and necrosis through many different mechanisms such as oxidative stress, elevation of intracellular ROS and nitric oxide levels, reduction of antioxidant capacity, downregulation of NF-kB, downregulation of HIF-1 $\alpha$ and survivin, activation of TRVP1, increasing pro-apoptotic proteins.

d. Anti-angiogenesis.

e. Topoisomerasa I and II inhibition may also play a role in cell cycle arrest and apoptosis [53], [54-58]

\section{Toxicity}

No serious studies have been conducted to determine the pharmacokinetics of EVO in superior mammals, or to determine tolerance and toxicity. It is known that it is hepatotoxic at high dose and there is also cumulative hepatotoxicity in mice $[59,60]$. The Evodia fruit extracts (the source of EVO) are extensively used in China in humans and one case of acute hepatotoxicity has been described with the nutritional supplement White Flood 
that contains EVO, but also many other plant extracts including Vinca alkaloids [61,62]. The mechanism of hepatotoxicity seems to be related to oxidative stress and alterations of mitochondrial permeability in liver cells of mice [60]. However the experiments of hepatotoxicity performed on mice used very high doses of Evodia extracts (LD50 $=10 \mathrm{~g} / \mathrm{kg}$ or above) [63] or $50 \mathrm{~g} / \mathrm{kg}$ [64].

\section{Are the clinically achievable concentrations of EVO enough for anti-tumor effects?}

A concentration of 10 to $20 \mu \mathrm{g} / \mathrm{ml}$ for 24 hours produces a $70 \%$ decrease in migration without modifying tumour growth in vitro. If this concentration is sustained for 48 hours a concentration and time dependent growth inhibition is achieved. Under these experimental conditions the number of lung metastases was diminished by $48 \%$ [65]. But concentrations as low as $1.25 \mu \mathrm{g} / \mathrm{ml}$ are sufficient to produce inhibition of migration [10]. MDA-MB-231 cells required higher concentrations to show cytotoxic effects: $30 \mu \mathrm{g} / \mathrm{ml}$ for 72 hours produced a decrease in cell viability of up to $77 \%$ [8]. We need to keep a concentration around $30 \mu \mathrm{g} / \mathrm{ml}$ at tumor level if we want to produce cytotoxicity. Is this possible? The oral administration of EVO in rats has an availability of $0.1 \%$ in plasma [66]. Supposing that the availability in humans is the same, we may assume that an oral dose of $1.000 \mathrm{mg}$ would achieve a concentration of $20 \mu \mathrm{g} / \mathrm{ml}$ in body fluids.

It remains to be seen if the concentration in body fluids is the same at the tumour microenvironment, because of limitations of blood vessels, and functional insufficiency of the new vessels formed during the process of angiogenesis. It may be presumed that tumour ischemia may play a role in reducing EVO's concentration in the tumour's microenvironment. $1.000 \mathrm{mg}$ per os seems a tolerable dose, because many of the over the counter nutritional supplements contain $500 \mathrm{mg}$ of EVO, and some prople take more than one pill a day. Ethanol extracts of EVO seem to produce a higher availability $[67,68]$. The plasma concentration of EVO peaks within $1 \mathrm{~h}$ after oral administration [69]. Wen et al. [70] developed a method to determine body fluids concentrations of EVO, so that it would be relatively simple to test the concentration of the drug in blood. New derivatives of EVO with better availability and better anti-cancer effects are under research [71,72].

\section{Discussion}

The lethality of cancer is mainly associated with its ability to produce metastasis. For a metastasis to develop, the cells must be able to migrate and invade. Also metastatic cells need migration as a mechanism to establish themselves in distant colonies. Therefore, reducing migratory capacity should be an essential part of cancer treatment. However, present day oncological treatments pay scarce attention to this issue. If there is a drug with very low toxicity that can substantially reduce migration, it should deserve more attention. There is overwhelming evidence indicating that EVO decreases migration and metastasis in low concentrations and in higher concentrations exerts cytotoxic effects in malignant cells with minimal toxicity for normal cells. There is also evidence that the "anti-migration concentration" is achievable with oral administration.

The cytotoxic effects that require higher concentrations, are not easy to achieve with oral administration and the standard pharmaceutical preparations. This is the reason why more effective pharmaceutical delivery systems are being investigated for this drug. In the event that bioavailability is improved, EVO would be a more potent cytotoxic than paclitaxel [12]. But here, we are limiting our expectations to the anti-migratory effects of EVO. EVO has also shown complementary effects with certain chemotherapeutics like camptothecin in ovarian cancer [57] and erlotinib in NSCLC with non mutated EGFR [58], with doxorubicin [73], with paclitaxel in gastric cancer cells [74], gemcitabine in pancreatic cancer [75], cisplatin in gastric cancer [76,77] and in reversing multidrug resistance in leukemic cells [78]. EVO`s ability to increase free radicals may also complement radiotherapy, and it has been experimentally tested [79-81]. A combination of evodiamine and nitrogen mustard has been developed; it showed antiproliferative activity without effects on peripheral mononuclear blood cells [82]. EVO and berberine decreased Mir-429 that acts as an oncogene in human colon cancer [83].

But all the above mentioned evidence was obtained in rodents and tissue culture. To the best of our knowledge there are no publications regarding the in vivo activity of EVO in superior mammals and humans. The bioavailability and metabolism in rodents is also well established, but this is not the case for humans. A daily dose of $500 \mathrm{mg}$ per os is well tolerated by humans, as it has been widely used at that dose under the label of "nutrient supplement" for weight loss. It is highly possible that twice that dose would be well tolerated too, and this would make it possible to achieve "anti-migratory" concentrations. The technology for measuring EVO`s plasmatic concentrations is also available. EVO derivatives have been synthesized with increased anti-cancer effects and with lower concentration requirements to achieve cytotoxicity [72].

Another important reason to consider EVO in the anti-cancer armamentarium is its ability to down regulate HIF- $1 \alpha$ which is a powerful driver of tumor progression and evolution. Berberine has shown synergistic activities with EVO in cancer cell cycle arrest and apoptosis [84], and the association of these two compounds would make it possible to reduce the high concentrations of EVO needed for its cytotoxic effects. Berberine has its own anticancer effects by inhibiting heparanase`s degradation of the extracellular matrix [85] and thus contributing to EVO`s ability to inhibit migration. The association of these two non toxic drugs may represent an important breakthrough in the battle against migration. The publications mentioned in this review, clearly show that EVO has interesting anti-tumor effects, not only as a "cancer cell killer" but as an inhibitor of migration, invasion and metastasis. 
Migration is a complex process in which many proteins participate. Src, inhibited by EVO, is an important player but to really acquire an "anti-migratory condition" other aspects of migration should be dealt with, like NHE-1, VGSCs and the low extracellular $\mathrm{pH}$ that favors the activity of proteolytic enzymes. Targeting migration should include an attack on these other players too. Fortunately, there are available drugs that target them: ameloride and its derivatives against NHE-1, anti-epileptics against VGSCs, proton pump inhibitors to raise extracellular matrix $\mathrm{pH}$ [86-95]. We believe that associating EVO and berberine with these other anti-migratory drugs may represent a useful partnership. We do not think that any isolated drug, with low toxicity can achieve a significant downturn of migration, but the coordinated association of a few, that act on the different essential proteins required for migration and on extracellular matrix factors like acidity, may do the job.

The complexity of migration is also represented by the fact that there are at least two different forms of migration: mesenchymal and amoeboid. Inhibiting one form of migration may lead to the adoption of the alternative mechanism. But both depend on actin reorganization [96]. Therefore EVO should handicap both types of migration, at least in theory. This needs further experimental confirmation. COX2 is a promoter of invasion and migration [97-99] and metastasis [100]. Celecoxib, a COX2 inhibitor is a modulator of the actin cytoskeleton [101] and an inhibitor of matrix metalloproteinase 2 and 9 [102] so that a synergistic activity with EVO on migration may be expected.

On the other hand, modifying cancer cell adhesion mechanisms may represent an interesting complementary mechanism to "anti-migratory treatment". Celastrol, a natural triterpene inhibits extracellular matrix adhesion of cancer cells inhibiting migration by a different mechanism than that of EVO [103,104], so that it should complement it. A frequent issue in the medical literature is that when the primary tumour is detected, metastases are usually on their way. This "too late" theory should not prevent us from using anti-migratory treatments. Even if it is "too late", primary tumours and metastasis, need migration as an essential condition for local invasion and distant colonization. Metastases need migration to really establish them in the new location. And they also need migration to invade and grow. And there is still the question of metastasis giving rise to new metastases.

Finally, the requirement of high concentrations for EVO's cytotoxic effects and problems with its bioavailability can be substantially corrected by modifications in sites 13 and 14 of the molecule [105] which would transform it into a new chemotherapeutic drug. Nanoparticle technology may also increase its absorption, concentration in body fluids and cytotoxic effects [106]. Some difficulties in the research of the combination of EVO and berberine have been solved: both can be determined in plasma simultaneously [107]. Using Evodia extracts the absorption of berberine was increased. The activation of vainilloid channels like
TRPV1 plays a role in cancer which at the present time is not very clear. Capsaicin is an activator of these channels and at the same time it acts as an inhibitor of VGSCs [108-109]. Blocking VGSCs is a mechanism to decrease the metastatic process $[110,111]$. EVO is an agonist of TRPV-1 in the same way as capsaicin. It remains to be investigated if it is also a VGSC inhibitor.

The last, but not the least question to consider is tumor hypoxia as a driver for tumor evolution. EVO has shown the ability to reduce the hypoxia response through down regulation of HIF-1 $\alpha$ [46]. At the same time berberine targets Sp1 (specifity protein 1) which is a transcription factor for HIF expression [112]. Sp1 is also one of the promoters of NHE-1 [113]. In spite of all the anti-cancer effects of EVO, it increases IL8 expression and adhesive molecules in gastric cancer cells. This may promote metastasis. On the other hand berberine decreased IL8 expression and decreased VCAM1[114]. Recently, a study of EVO`s possible cardiotoxicity, showed that EVO may be cytotoxic for heart muscle cells in neonatal rats and zebra fish larvae, but there are no studies regarding adult cardiomyocites [115] and there are a diversity of publications showing cardiovascular benefits from EVO [5,116-123]. All this evidence reinforce the concept of the association of EVO and berberine, that allows a lower dose of EVO.

As a summary, and to define cell death pathways and migratory pathways affected by EVO, Table 4 is introduced. This Table 4 pretends to show with more details how the EVO induced cell arrest, through caspase dependent and independent mechanisms, is produced and also the mechanisms behind migration inhibition [124-140].

\section{Conclusion}

The importance of migration in tumor development and progression cannot be overemphasized and having a drug like EVO with its low toxicity that may interfere with both, is not a minor fact. Therefore, Evo should be tested in humans to establish the plasma concentrations, because all the published pharmacodynamic reports were based on rodents. Whether alone or associated with berberine, EVO deserves to be tested in well designed clinical trials for the treatment of cancer and prevention of metastasis [141-189].

\section{Future Perspectives}

Anti-migratory treatments have not arrived to standard cancer care yet. But most of the required pharmacological resources are almost available. Then, it is only a matter of time and medical "fashion trends" for it to happen. In this case EVO or its derivatives, whether or not combined with berberine, will have a place in anti-migrant treatments. It will possibly form part of a multi-drug scheme against migration, integrated with ameloride derivatives, voltage gated sodium channel blockers, v-ATP-ase proton pump inhibitors and COX2 inhibitors. Certain shortcomings of EVO's bioavailability may be solved with new more soluble compounds or different preparation forms. The almost absent toxicology of EVO at anti-migratory doses make it an ideal drug for this purpose. Even 
if EVO's cytotoxic effect is not emphasized in this study, because it requires a concentration that may be difficult to achieve in vivo, it is quite probable that EVO can be developed as a full blown cytotoxic chemotherapeutic drug.

\section{References}

1. Jiang J, Hu C (2009) Evodiamine: a novel anti-cancer alkaloid from Evodia rutaecarpa. Molecules 14(5): 1852-1859.

2. Campbell BI, Colquhoun RJ, Zito G, Nic Martinez, Kristina kendall, et al. (2016) The effects of a fat loss supplement on resting metabolic rate and hemodynamic variables in resistance trained males: a randomized, double-blind, placebo-controlled, cross-over trial. Journal of the International Society of Sports Nutrition 13(1): 13-14.

3. Schwarz NA, Spillan M, La Bounty P (2013) Capsaicin and evodiamine ingestion does not augment energy expenditure and fat oxidation at rest or after moderately-intense exercise. Nutrition Research 33(2): 10341042 .

4. (2016) ANSES (French Agency for Food, Environmental and Occupational Health \& Safety), France.

5. Kobayashi Y, Hoshikuma K, Nakano Y, Yokoo Y, Kamiya T (2001) The positive inotropic and chronotropic effects of evodiamine and rutaecarpine, indoloquinazoline alkaloids isolated from the fruits of Evodia rutaecarpa, on the guinea-pig isolated right atria: possible involvement of vanilloid receptors. Planta medica 67(3): 244-248.

6. Shoji N, Umeyama A, Takemoto T, Kajiwara A, Ohizumi Y (1986) Isolation of evodiamine, a powerful cardiotonic principle, from Evodia rutaecarpa Bentham (Rutaceae). Journal of pharmaceutical sciences 75(6): 612613.

7. Sun C, Zhang G, Luan S, Luan C, Shao H, et al. (2016) Evodiamine inhibits the proliferation of leukemia cell line K562 by regulating peroxisome proliferators-activated receptor gamma (PPARy) pathway. J Recept Signal Transduct Res 36(4): 422-428.

8. Du J, Wang XF, Zhou QM, Zhang TL, Lu YY, et al. (2013) Evodiamine induces apoptosis and inhibits metastasis in MDA-MB-231 human breast cancer cells in vitro and in vivo. Oncology reports 30(2): 685-694.

9. Ogasawara M, Matsunaga T, Takahashi S, Saiki I, Suzuki H (2002) Antiinvasive and metastatic activities of evodiamine. Biol Pharm Bull 25: 1491- 1493.

10. Ogasawara M, Matsubara T, Suzuki H (2001) Screening of natural compounds for inhibitory activity on colon cancer cell migration. Biol Pharm Bull 24: 720-723.

11. Xu ML, Li G, Moon DC, Woo MH, Lee ES, et al. (2006) Cytotoxicity and DNA topoisomerase inhibitory activity of constituents isolated from the fruits of Evodia officinalis. Arch Pharm Res 29(7): 541-547.

12. Liao CH, Pan SL, Guh JH, Chang YL, pai HC, et al. (2005) Antitumor mechanism of evodiamine, a constituent from Chinese herb Evodiae fructus, in human multipledrug resistant breast cancer NCI/ADR-RES cells in vitro and in vivo. Carcinogenesis 26: 968-975.

13. Fei XF, Wang BX, Li TJ, Tashiro S, Minami M, et al. (2003) Evodiamine, a constituent of Evodiae Fructus, induces anti-proliferating effects in tumor cells. Cancer Sci 94 : 92-98.

14. Lee TJ, Kim EJ, Kim S, Jung EM, Park JW, et al. (2006) Caspase-dependent and caspase-independent apoptosis induced by evodiamine in human leukemic U937 cells. Molecular cancer therapeutics 5(9): 2398-2407.

15. Mohan V, Agarwal R, Singh RP (2016) A novel alkaloid, evodiamine causes nuclear localization of cythocrome-c and induces apoptosis independent of p53 in human lung cancer cells. Biochem Biophys Res Commun 477(4): 1065-1071.
16. Wen Z, Feng S, Wei L, Wang Z, Hong D, et al. (2015) Evodiamine, a novel inhibitor of the Wnt pathway, inhibits the self-renewal of gastric cancer stem cells. International journal of molecular medicine 36(6): 16571663.

17.Zhang Y, Wu LJ, Tashiro S, Onodera S, Ikejima T (2004) Evodiamine induces tumor cell death through different pathways: apoptosis and necrosis. Acta Pharmacol Sin 25(1): 83-89.

18. Wang C, Li S, Wang MW (2010) Evodiamine-induced human melanoma A375-S2 cell death was mediated by PI3K/Akt/caspase and Fas-L/NFkappaB signaling pathways and augmented by ubiquitin-proteasome inhibition Toxicol. In Vitro 24: 898-904.

19. Huang H, Zhang Y, Liu X, Liz Z, Xu W, et al. Acid sphingomyelinase contributes to evodiamine-induced apoptosis in human gastric cancer SGC-7901 cells. DNA Cell Biol 30(6): 407-412.

20. Wang C, Wang MW, Tashiro S, Shin ichi T, Satoshi O, Takashi I (2005) Roles of SIRT1 and phosphoinositide 3-OH kinase/protein kinase C pathways in evodiamine-induced human melanoma A375-S2 cell death. J Pharmacol Sci 97: 494-500.

21. Mader CC, Oser M, Magalhaes MA, Jose Javier Bravo Cordero, John Condeelis, et al (2011) An EGFR-Src-Arg-Cortactin pathway mediates functional maturation of invadopodia and breast cancer cell invasion. Cancer Res 71(5): 1730- 1741.

22. Oser M, Yamaguchi H, Mader CC, Bravo-Cordero JJ, Arias M, et al. (2009) Cortactin regulates cofilin and N-WASp activities to control the stages of invadopodium assembly and maturation. J Cell Biol 186(4): 571-587.

23. Clark ES, Whigham AS, Yarbrough WG, Weaver AM (2007) Cortactin is an essential regulator of matrix metalloproteinase secretion and extracellular matrix degradation in invadopodia. Cancer Res 67(9): 4227- 4235 .

24. Patel AS, Schechter GL, Wasilenko WJ, Somers KD (1998) Overexpression of EMS1/cortactin in NIH3T3 fibroblasts causes increased cell motility and invasion in vitro. Oncogene 16(25): 3227-3232.

25. Rothschild BL, Shim AH, Ammer AG, Kelley LC, Irby KB, et al. (2006) Cortactin overexpression regulates actin-related protein $2 / 3$ complex activity, motility, and invasion in carcinomas with chromosome 11q13 amplification. Cancer Res 66: 8017- 8025.

26. Liao W, Li B, Li L, Yan L, Wang Z, et al. (2015) Erk1/2, CDK8, Src and Ck1e Mediate Evodia rutaecarpa Induced Hepatotoxicity in Mice. Chinese Medicine 6(2): 97-108.

27. Verlicchi A, Karachaliou N, Lazzari C, Carles Codony Servat, Ana Gimenez Capitan, et al. (2017) P3. 01-038 STAT3 and Src-YAP1 Inhibition Results in Greater Necitumumab Sensitivity in Lung Squamous Cell Carcinoma. Journal of Thoracic Oncology 12(1): S1143.

28. Yang J, Cai X, Lu W, Hu C, Xu X, et al. (2013) Evodiamine inhibits STAT3 signaling by inducing phosphatase shatterproof 1 in hepatocellular carcinoma cells. Cancer letters 328(2): 243-251.

29. Wu CM, Li TM, Tan TW, Yi cjin Fong, Chin Hsin Tang, et al. (2013) Berberine Reduces the Metastasis of Chondrosarcoma by Modulating the alpha v beta 3 Integrin and the PKC delta , c-Src, and AP-1 Signaling Pathways. Evid Based Complementary Altern Med 2013(2013): 423164.

30. Chen MC, Yu CH, Wang SW, Pu HF, Kan SF, et al. (2010) Anti-Proliferative Effects of Evodiamine on Human Thyroid Cancer Cell Line ARO. Journal of cellular biochemistry 110(6): 1495-1503.

31. Zhang C, Fan X, Xu X, Yang X, Wang X, et al. (2010) Evodiamine induces caspase-dependent apoptosis and $S$ phase arrest in human colon lovo cells. Anti-cancer drugs 21(8): 766-776.

32. Chien CC, Wu MS, Shen SC, Ko CH, Chen CH, et al. (2014) Activation of JNK contributes to evodiamine-induced apoptosis and G2/M arrest in human 
colorectal carcinoma cells: a structure-activity study of evodiamine. PloS one 9(6): e99729.

33. Wang XN, Han X, Xu LN, Yin LH, Xu YW, et al. (2008) Enhancement of apoptosis of human hepatocellular carcinoma SMMC-7721 cells through synergy of berberine and evodiamine. Phytomedicine 15(12): 10621068.

34. Yang J, Wu LJ, Tashino S, Onodera S, Ikejima T (2008) Reactive oxygen species and nitric oxide regulate mitochondria-dependent apoptosis and autophagy in evodiamine-treated human cervix carcinoma HeLa cells. Free Radic Res 42(5): 492-504.

35. Yang J, Wu LJ, Tashiro S, Onodera S, Ikejima T (2007) Critical roles of reactive oxygen species in mitochondrial permeability transition in mediating evodiamine-induced human melanoma A375-S2 cell apoptosis. Free Radic Res 41(10): 1099-1108.

36. Sánchez MG, Sánchez AM, Collado B, Malagarie Cazenave S, Olea N, et al. (2005) Expression of the transient receptor potential vanilloid 1 (TRPV1) in LNCaP and PC-3 prostate cancer cells and in human prostate tissue. European journal of pharmacology 515(1): 20-27.

37. Pearce LV, Petukhov PA, Szabo T, Kedei N, Bizik F, et al. (2004) Evodiamine functions as an agonist for the vanilloid receptor TRPV1. Org Biomol Chem 2: 2281- 2286

38. Amantini C, Ballarini P, Caprodossi S, Nabissi M, Morelli MB, et al. (2009) Triggering of transient receptor potential vanilloid type 1 (TRPV1) by capsaicin induces Fas/CD95-mediated apoptosis of urothelial cancer cells in an ATM-dependent manner. Carcinogenesis 30(8): 1320-1329.

39. Santoni G, Caprodossi S, Farfariello V, Sonia Liberati, Angela Gismondi, et al. (2012) Antioncogenic effects of transient receptor potential vanilloid 1 in the progression of transitional urothelial cancer of human bladder. ISRN urology 2012: 458238.

40. Sanchez AM, Sanchez MG, Malagarie Cazenave S, Olea N, Díaz-Laviada I (2006) Induction of apoptosis in prostate tumor PC-3 cells and inhibition of xenograft prostate tumor growth by the vanilloid capsaicin. Apoptosis 11(1): 89-99.

41. Ziglioli F, Frattini A, Maestroni U, F Dinale (2009) Vanilloid-mediated apoptosis in prostate cancer cells through aTRPV-1 dependent and a TRPV-1-independent mechanism. Acta Bio Medica Atenei Parmensis 80(1): 13-20.

42. Morelli MB, Nabissi M, Amantini C, Farfariello V, Ricci-Vitiani L, et al. (2012) The transient receptor potential vanilloid-2 cation channel impairs glioblastoma stem-like cell proliferation and promotes differentiation. International journal of cancer 131(7): E1067-1077.

43. Tu YJ, Fan X, Yang X, Zhang C, Liang HP (2013) Evodiamine activates autophagy as a cytoprotective response in murine Lewis lung carcinoma cells. Oncol Reports 29(2): 481-490.

44. Yamahara J, Yamada T, Kitani T, Yoshikazu Naitoh, Hajime Fujimura, et al. (1989) Antianoxic action of evodiamine, an alkaloid in Evodia tutaecarpa fruit. Journal of Ethnopharmacology 27(1-2): 185-192.

45. Chiou WF, Chen CF (2002) Pharmacological profile of evodiamine in isolated rabbit corpus cavernosum. European Journal of Pharmacology 446(1-3): 151-159.

46. Liu YN, Pan SL, Liao CH, Huang Der Yi, Guh Jih Hwa, et al. (2009) Evodiamine represses hypoxia-induced inflammatory proteins expression and hypoxia-inducible factor $1 \alpha$ accumulation in RAW264. 7. Shock 32(3): 263-269.

47. Wang RB, Zhou SS, Li SS (2011) Cancer therapeutic agents targeting hypoxia-inducible factor-1. Current medicinal chemistry 18(21): 31683189.

48. Huang J, Chen ZH, Ren CM, Dong-Xu Wang, Shuang Xue Yuan, et al (2015) Antiproliferation effect of evodiamine in human colon cancer cells is associated with IGF-1/HIF-1 $\alpha$ downregulation. Oncology reports 34(6): 3203-3211.

49. Shyu KG, Lin S, Lee CC, Chen E, Lin LC, et al. (2006) Evodiamine inhibits in vitro angiogenesis: Implication for antitumorigenicity. Life Sci 78(19): 2234-2243.

50. Shi L, Yang F, Luo F, Yi Lu, Feng zang, et al. (2016) Evodiamine exerts anti-tumor effects against hepatocellular carcinoma through inhibiting $\beta$-catenin-mediated angiogenesis. Tumor Biology 37(9): 12791-12803.

51. Jara Oseguera A, Simon SA, Rosenbaum T (2008) TRPV1: On the road to pain relief. Curr Mol Pharmacol 1(3): 255- 269.

52. Weber LV, Al Refae K, Wölk G, Gabriele Bonatz, Janine Altmüller, et al. (2016) Expression and functionality of TRPV1 in breast cancer cells. Breast Cancer : Targets and Therapy 8: 243-252.

53. Hong JY, Park SH, Min HY, Hyen Joo Park, Sang Kook Lee, et al. (2014) Anti-proliferative effects of evodiamine in human lung cancer cells. Journal of cancer prevention 19(1): 7-13.

54. Dong G, Sheng C, Wang S, Zhenyuan Miao, Jianzhong Yao, et al. (2010) Selection of evodiamine as a novel topoisomerase I inhibitor by structure-based virtual screening and hit optimization of evodiamine derivatives as antitumor agents. Journal of medicinal chemistry 53(21): 7521-7531.

55. Pan X, Hartley JM, Hartley JA, White KN, Wang Z, et al. (2012) Evodiamine, a dual catalytic inhibitor of type I and II topoisomerases, exhibits enhanced inhibition against camptothecin resistant cells. Phytomedicine 19(7): 618-624.

56. Fang K, Dong GQ, Gong H, Nai Liu, Zeng gang Li, et al. (2014) Design, synthesis and biological evaluation of E-ring modified evodiamine derivatives as novel antitumor agents. Chinese Chemical Letters 25(7): 978-982.

57. Lee YC, Lee CH, Tsai HP, Herng Wei An, Chi Ming Lee, et al. (2015) Targeting of topoisomerase I for prognoses and therapeutics of Camptothecin-Resistant ovarian cancer. PloS one 10(7): e0132579.

58. Li Y, Pan Y, Wu Wj, Mao SY, Sun J, et al. (2016) Evodiamine induces apoptosis and enhances apoptotic effects of erlotinib in wild-type EGFR NSCLC cells via S6K1-mediated Mcl-1 inhibition. Med Oncol 33(2): 16.

59. Yang XW, Zhang H, Li M, Du LJ, Yang Z, et al. (2006) Studies on the alkaloid constituents of Evodia rutaecarpa (Juss) Benth var. bodinaieri (Dode) Huang and their acute toxicity in mice. Journal of Asian natural products research 8(8): 697-703.

60. Cai Q Wei J, Zhao W, Si Shi, Yu Zhang, et al. (2014) Toxicity of Evodiae fructus on rat liver mitochondria: the role of oxidative stress and mitochondrial permeability transition. Molecules 19(12): 21168-21182.

61. Cohen SM, Heywood E, Pillai A, Joseph Ahn (2012) Hepatotoxicity associated with the use of White Flood, a nutritional supplement. Pract Gastroenterol 10: 45-47.

62. Teschke R, A Wolff, C Frenzel, J Schulze (2014) Traditional Chinese Medicine induced liver injury. Journal of clinical and translational hepatology 2(2): 80.

63. Yang XV (2008) Toxicological assesment on safety of water and 70\% ethanolic extracts of nearly ripe fruit of Evodia rutaecarpa. Zhongguo Zhong Yao Za Zhi 33(11): 1317-1321.

64. Ogasawara M, Matsubara T, Suzuki H (2001) Inhibitory effects of evodiamine on in vitro invasion and experimental lung metastasis of murine colon cancer cells. Biol Pharm Bull 24(8): 917- 920.

65. Zhou Q Zhang Q Jin RM (2011) Time-effect and dose-effect of Evodia rutaecarpa on hepatotoxicity in mice. Chinese Journal of Experimental Traditional Medical Formulae 17(10): 232-235. 
66. Shyr MH, Lin LC, Lin TY, Tzu Yang Lin, Tung Hu Tsai (2006) Determination and pharmacokinetics of evodiamine in the plasma and feces of conscious rats. Analytica chimica acta 558(1): 16-21.

67. Cai QY, Li WR, Wei JJ, SQ Mi, NS Wang (2014) Antinociceptive activity of aquos and alcohol extracts of Evodia rutaecarpa. Indian J Pharm Sci 76(3): 235-239.

68. Ko HC, Wang YH, Liou KT, Chen CM, Chen CH, et al. (2007) Antiinflammatory effects and mechanisms of the ethanol extract of Evodia rutaecarpa and its bioactive components on neutrophils and microglial cells. Eur J Pharmacol 555(2-3): 211-217.

69. Yu H, Jin H, Gong W, Zhanli Wang, Huaping Liang, (2013) Pharmacological actions of multi-target-directed Evodiamine. Molecules 18: 1826-1843.

70. Wen D, Li C, Liu Y, Liao Y, Lui H (2006) Determination of evodiamine and rutecarpine in human serum by liquid chromatography- tandem mass spectrometry. Analytical and bioanalytical chemistry 385(6): 10751081

71. Tan Q Liu S, Chen X, Mingjun Wu, Hong Wang, et al. (2012) Design and evaluation of a novel evodiamine-phospholipid complex for improved oral bioavailability. Aaps Pharmscitech 13(2): 534-547.

72. Guoqiang Dong, Shengzheng Wang, Zhenyuan Miao, Jianzhong Yao, Yongqiang Zhang, et al. (2012) New tricks for an old natural product: discovery of highly potent evodiamine derivatives as novel antitumor agents by systemic structure- activity relationship analysis and biological evaluations. Journal of medicinal chemistry 55(17): 7593-7613.

73. Wang S, Wang L, Shi Z, Zong Z, Chen M, et al. (2014) Evodiamine synergizes with doxorubicin in the treatment of chemoresistant human breast cancer without inhibiting P-glycoprotein. PloS one 9(5): e97512.

74. Zhang YX, Ge YK (2014) Study on Synergetic Anti-Tumor Effect of Evodiamine and Paclitaxel in SGC-7901 Cells. Journal of Jilin Agricultural University 3: 012.

75. Wei Tian Wei, Hui Chen, Zhao Hong Wang, Zhong Lin Ni, Hai Bin Liu, et al. (2012) Enhanced antitumor efficacy of gemcitabine by evodiamine on pancreatic cancer via regulating PI3K/Akt pathway. Int J Biol Sci 8(1): $1-14$.

76. Qing Feng Tang, Jian Sun, Hui Yu, Xiao Jing Shi, Rong Lv, et al. (2016) The Zuo Jin Wan Formula Induces Mitochondrial Apoptosis of Cisplatin-Resistant Gastric Cancer Cells via Cofilin-1. Evidence-Based Complementary and Alternative Medicine 2016(2016).

77. Muhammad Khan, Javed Iqbal Qazi, Azhar Rasul, Yongchen Zheng, Tonghui Ma (2013) Evodiamine induces apoptosis in pancreatic carcinoma PANC-1 cells via NF $\kappa B$ inhibition. Bangladesh Journal of Pharmacology 8(1): 8-14.

78. LI Xiao peng, FENG Zi qiang, SHI Xue ping, LI Jing (2016) Experimental study of evodiamine on reversing multi-drug resistance of K562/Adr cells.

79. Chengqi Hu, Xuexiang Gao, Yuanyuan Han, Qi Guo, Kailiang Zhang, et al. (2016) Evodiamine sensitizes BGC-823 gastric cancer cells to radiotherapy in vitro and in vivo. Molecular medicine reports 14(1): 413-419.

80. Feng H, Guo B, Kong X, Wu B (2016) Evodiamine enhances the radiosensitivity of esophageal squamous cell cancer Eca-109 cells. Xi Bao Yu Fen Zi Mian Yi Xue Za Zhi 32(7): 940-944.

81. Jie Li, Kai liang Zhang, Cheng qi Hu, Yuan-yuan Han, Zheng-qiang Kang, et al. (2014) Inhibitory effect of evodiamine combined with radiotherapy on the growth of xenografts of human tongue squamous-cell carcinoma Tca-8113 cells in nude mice. Tumor 34(2).

82. Xu Hu, Yan Wang, Jingjing Xue, Tong Han, Runwei Jiao, et al. (2017) Design and synthesis of novel nitrogen mustard-evodiamine hybrids with selective antiproliferative activity. Bioorganic \& medicinal chemistry letters 27(22): 4989-4993.

83. Liu H, Huang C, Wu L, Bin W (2016) Effect of evodiamine and berberine on miR-429 as an oncogene in human colorectal cancer. OncoTargets and Therapy 9: 4121- 4127.

84. Huang C1, Liu H, Gong XL, Wu Ly, Wen B (2017) Effect of evodiamine and berberine on the interaction between DNMTs and target microRNAs during malignant transformation of the colon by TGF- $\beta 1$. Oncol Rep 37(3): 1637-1645.

85. Yan L, Yan K, Kun W, Xu L, Ma Q, et al. (2013) Berberine inhibits the migration and invasion of T24 bladder cancer cells via reducing the expression of heparanase. Tumour Biol 34: 215-221.

86. Harguindey S, Arranz JL, Orozco JD, Rauch C, Fais S, et al (2013) Cariporide and other new and powerful NHE1 inhibitors as potentially selective anticancer drugs- an integral molecular/biochemical/ metabolic/clinical approach after one hundred years of cancer research. Journal of translational medicine 11(1): 282.

87. Megan Walsh, Stefano Fais, Enrico Pierluigi Spugnini, Salvador Harguindey, Tareq Abu Izneid, et al. (2015) Proton pump inhibitors for the treatment of cancer in companion animals. Journal of Experimental \& Clinical Cancer Research 34(1): 93.

88. Fais S, Venturi G, Gatenby B (2014) Microenvironmental acidosis in carcinogenesis and metastases: new strategies in prevention and therapy. Cancer and Metastasis Reviews 33(4): 1095-1108.

89. Salvador Harguindey, Julián D Polo Orozco, Mariso Cuenca, Mercedes Cano Fernandez, Jose L Arranz, (2014) New and powerful NHE1 inhibitors as potential anticancer drugs in bedside oncology: A prospective program of preclinical studies in cats and dogs with spontaneous malignant tumors, Spain.

90. De Milito A, Iessi E, Logozzi M, Lozupone F, Spada M, et al. (2007) Proton pump inhibitors induce apoptosis of human B-cell tumors through a caspase-independent mechanism involving reactive oxygen species. Cancer research 67(11): 5408-5417.

91. Fais S, De Milito A, You H (2007) Targeting vacuolar H+-ATPases as a new strategy against cancer. Cancer research 67(22): 10627-10630.

92. De Milito A, Canese R, Marino ML, Borghi M, Iero M, et al. (2010) pHdependent antitumor activity of proton pump inhibitors against human melanoma is mediated by inhibition of tumor acidity. International journal of cancer 127(1): 207-219.

93. Yang M, Kozminski DJ, Wold LA, Modak R, Calhoun JD, et al. (2012) Therapeutic potential for phenytoin: targeting Nav1. 5 sodium channels to reduce migration and invasion in metastatic breast cancer. Breast cancer research and treatment 134(2): 603-615.

94. Nelson M, Yang M, Dowle AA, Thomas JR, Brackenbury WJ, et al. (2015) The sodium channel-blocking antiepileptic drug phenytoin inhibits breast tumour growth and metastasis. Molecular cancer 14(1): 13.

95. Fiske JL, Fomin VP, Brown ML, Duncan RL, Sikes RA (2006) Voltagesensitive ion channels and cancer. Cancer and Metastasis Reviews 25(3): 493-500.

96. Yamazaki D, Kurisu S, Takenawa T (2005) Regulation of cancer cell motility through actin reorganization. Cancer science 96(7): 379-386.

97. Eun Jeong Lee, Eun Mi Choi, So Ra Kim, Jung Hea Park, Hyunsook Kim, et al. (2007) Cyclooxygenase- 2 promotes cell proliferation, migration and invasion in U2OS human osteosarcoma cells. Experimental \& molecular medicine 39(4): 469.

98. Singh B, Berry JA, Shoher A, Vijay Ramakrishnan, Anthony Lucci (2005) COX-2 overexpression increases motility and invasion of breast cancer cells. International journal of oncology 26(5): 1393-1399. 
99. Banu SK, Lee J, Speights Jr VO, Starzinski Powtiz, JA Arsoh (2007) Cyclooxygenase- 2 regulates survival, migration, and invasion of human endometriotic cells through multiple mechanisms. Endocrinology 149(3): 1180-1189.

100. Li G, Yang T, Yan J (2002) Cyclooxygenase-2 increased the angiogenic and metastatic potential of tumor cells. Biochemical and biophysical research communications 299(5): 886-890.

101. Behr CA, Hesketh AJ, Barlow M (2015) Celecoxib inhibits Ewing sarcoma cell migration via actin modulation. Journal of Surgical Research 198(2): 424-433.

102. Li WW, Long GX, Liu DB (2014) Cyclooxygenase-2 inhibitor celecoxib suppresses invasion and migration of nasopharyngeal carcinoma cell lines through a decrease in matrix metalloproteinase- 2 and-9 activity. Pharmazie 69(2): 132-137.

103. Zhu H, Liu XW, Cai TY (2010) Celastrol Acts as a Potent Antimetastatic Agent Targeting 1 Integrin and Inhibiting Cell-Extracellular Matrix Adhesion, in Part via the p38 Mitogen-Activated Protein Kinase Pathway. Journal of Pharmacology and Experimental Therapeutics 334(2): 489-499.

104. Cascão R, Fonseca JE, Moita LF (2017) Celastrol: A Spectrum of Treatment Opportunities in Chronic Diseases. Frontiers in Medicine 4: 69.

105. Song S, Chen Z, Li S (2013) Design, synthesis and evaluation of N13substituted evodiamine derivatives against human cancer cell lines. Molecules 18(12): 15750-15768

106. Zou L, Chen F, Bao J (2016) Preparation, characterization, and anticancer efficacy of evodiamine-loaded PLGA nanoparticles. Drug Delivery 23(3): 908-916.

107. Fei Y and Rui Y (2011) Simultaneous Determination of Berberine and Evodiamine in Dog Plasma by LC-ESI-MS Method and Its Application to Pharmacokinetics. Journal of Chromatographic Science 49(3): 198202.

108. Liu L, Oortgiesen M, Li L, Simon SA (2001) Capsaicin inhibits activation of voltage-gated sodium currents in capsaicin-sensitive trigeminal ganglion neurons. Journal of neurophysiology 85(2): 745-758.

109. Brackenbury WJ (2012) Voltage-gated sodium channels and metastatic disease. Channels (Austin) 6(5): 352-361.

110. Roger S, Rollin J, Barascu A (2007) Voltage-gated sodium channels potentiate the invasive capacities of human non-small-cell lung cancer cell lines. Int J Biochem Cell Biol 39(4): 774-786.

111. Bennett ES, Smith BA, Harper JM (2004) Voltage-gated Na + channels confer invasive properties on human prostate cancer cells. Pflugers Arch 447(6): 908-914.

112. Chen J, Wu FX, Luo HL (2016) Berberine upregulates miR-22-3p to suppress hepatocellular carcinoma cell proliferation by targeting Sp1. Am J Transl Res 8(11): 4932-4941.

113. Okorokova Façanha AL, dos Reis MC, Montero-Lomeli M (2000) Structural study of the porcine $\mathrm{Na}+\mathrm{H}+$ exchanger NHE1 gene and its 5 -flanking region. Molecular and Cell Biochemistry 210(1-2): 91-99.

114. Shi HL, Wu XJ, Liu Y, Xie JQ (2013) Berberine counteracts enhanced IL-8 expression of AGS cells induced by evodiamine. Life sciences 93(22): 830-839.

115. Yang W, Ma L, Li S, Cui K, Lei L, Ye Z (2017) Evaluation of the cardiotoxicity of evodiamine in vitro and in vivo. Molecules 22(6): 943.

116. Rang WQ, Du YH, Hu CP (2004) Protective effects of evodiamine on myocardial ischemia-reperfusion injury in rats. Planta medica 70(12): $1140-1143$

117. Li F, Yuan Y, Zhang N, Wu Q Li J, Zhou M, Yang Z, Tang Q (2017) Evodiamine attenuates pressure overload-induced cardiac hypertrophy. Int J Clin Exp Med 10(7): 10202-10213.
118. Jia S, Hu C (2010) Pharmacological effects of rutaecarpine as a cardiovascular protective agent. Molecules 15(3): 1873-1881.

119. He N, Gong QH, Zhang F, Zhang JY, Lin SX et al. (2017) Evodiamine inhibits angiotensin II-induced rat cardiomyocyte hypertrophy. Chinese journal of integrative medicine Sep 5: 1-7.

120. Jiang XX, Liu GY, Lei H, Li ZL, Feng QP etal. (2018) Activation of transient receptor potential vanilloid 1 protects the heart against apoptosis in ischemia/reperfusion injury through upregulating the PI3K/Akt signaling pathway. International journal of molecular medicine 41(3): 1724-1730.

121. Yong-shuang GA, An-sheng SU, Na HE, WU Qin, Yang Dan-li (2011) Inhibitory Effect of the Extracts of Euodiae Fructus on Right Ventricular Hypertrophy and Calcineurin of Rats. China Pharmacy 27.

122. Yi HH, Rang WQ, Deng PY, Hu CP, Liu GZ, et al. (2004) Protective effects of rutaecarpine in cardiac anaphylactic injury is mediated by CGRP. Planta Med 70(12): 1135-1139.

123. Vemula P, Gautam B, S Abela G, H Wang D (2014) Myocardial ischemia/ reperfusion injury: potential of TRPV1 agonists as cardioprotective agents. Cardiovascular \& Haematological Disorders-Drug Targets (Formerly Current Drug Targets-Cardiovascular \& Hematological Disorders) 14(1): 71-78.

124. Wang C, Wang MW, Tashiro SI, Onodera S, Ikejima T (2005) Evodiamine induced human melanoma A375-S2 cell death partially through interleukin 1 mediated pathway. Biological and Pharmaceutical Bulletin 28(6): 984-989.

125. Wei J, Li Z, Yuan F (2014) Evodiamine might inhibit TGF-beta1-induced epithelial-mesenchymal transition in NRK52E cells via Smad and PPAR-gamma pathway. Cell biology international 38(7): 875-880.

126. Rebhun JF, Roloff SJ, Velliquette RA, Missler SR (2014) Identification of evodiamine as the bioactive compound in evodia (Evodia rutaecarpa Benth) fruit extract that activates human peroxisome proliferatoractivated receptor gamma (PPAR $\gamma$ ). Fitoterapia 101: 57-63.

127. Sui H, Zhou LH, Zhang YL, Jian Ping H, Xian Liu, et al. (2016) Evodiamine Suppresses ABCG2 Mediated Drug Resistance by Inhibiting p50/p65 NF- $\mathrm{KB}$ Pathway in Colorectal Cancer. Journal of cellular biochemistry 117(6): 1471-1481.

128. Zhu LH, Bi W, Liu XD, JF Li, Ying Ya Wu, et al. (2011) Induction of apoptosis by evodiamine involves both activation of mitotic arrest and mitotic slippage. Oncology reports 26(6): 1447-1455.

129. Chen CY, Su KH, Kuan-I Lee, Jeng Wei, Tzong-Shyuan Lee, et al. (2012) Implication of AMP-activated protein kinase in transient receptor potential vanilloid type 1-mediated activation of endothelial nitric oxide synthase. Mol Med 18: 805-815.

130. Chen ZF, Zhang ZJ, Yi JY, Zhang Lu, Yang Zhuan-bo, et al. (2012) Research on the New Mechanism of Evodiamine Activating AMPK . Journal of Nanjing University of Traditional Chinese Medicine 4: 14.

131. Lv Z, Zhao D, Liu R, Guo J, Lin Y, et al. (2016) Evodiamine inhibits proliferation of human papillary thyroid cancer cell line $\mathrm{K} 1$ by regulating of PI3K/Akt signaling pathway. Int J Clin Exp Me 9(8): 15216-15225.

132. Chao DC, Lin LJ, Kao ST, Huang HC, Chang CS, et al. (2011) Inhibitory effects of Zuo-Jin-Wan and its alkaloidal ingredients on activator protein 1, nuclear factor- $\mathrm{kB}$, and cellular transformation in HepG2 cells. Fitoterapia 82(4): 696-703.

133. Chang JR, Chen WW, Wang JH (2011) Effects of Evodiamine and Berberine Hydrochloride on Telomerase Activity of Human Colorectal Cancer Cell Line HT29. Liaoning Journal of Traditional Chinese Medicine 7: 31.

134. Wang SP, Chen MW, Wang YT (2012) Tumor Suppressive Activity of Evodiamine in Breast Cancer Cells via Inhibition of Ras/MEK/ERK Pathway and Activation of PPAR $\gamma$. Planta Medica 78(05): 79. 
135. Lin L, Ren L, Wen L, Yu Wang, Jin Qi (2016) Effect of evodiamine on the proliferation and apoptosis of A549 human lung cancer cells. Molecular medicine reports. 14(3): 2832-2838.

136. Brisson L, Driffort V, Benoist L, Poet M, Counillon L, et al. (2013) Nav1.5 $\mathrm{Na}+$ channels allosterically regulate the NHE-1 exchanger and promote the activity of breast cancer cell invadopodia. J Cell Sci $126(\mathrm{Pt}$ 21): 4835-4842.

137. Heo SK, Yun HJ, Yi HS, Eui-Kyu Noh, Sun Dong Park, et al. (2009) Evodiamine and rutaecarpine inhibit migration by LIGHT via suppression of NADPH oxidase activation. Journal of cellular biochemistry 107(1): 123-33.

138. Wu QQ, Xiao Y, Jiang XH, Yuan Y, Yang Z, et al. (2017) Evodiamine attenuates TGF- $\beta 1$-induced fibroblast activation and endothelial to mesenchymal transition. Mol Cell Biochem 430(1-2): 81-90.

139. Ahrens W, Siani A, Adan R, De Henauw S, Eiben G (2017) Cohort Profile: The transition from childhood to adolescence in European childrenhow I. Family extends the IDEFICS cohort nt J Epidemiol 46(5): 13941395.

140. Ge X, Chen S, Liu M, Tingming Liang, Chang Liu (2015) Evodiamine Attenuates PDGF-BB-Induced Migration of Rat Vascular Smooth Muscle Cells through Activating PPARy. Int J Mol Sci 16(12): 2818028193.

141. Zhang Y, Zhang QH, Tashiro S, Onodera S, Ikejima T (2004) Atypical apoptosis in L929 cells induced by evodiamine isolated from Evodia rutaecarpa. J Asian Nat Prod Res 6(1): 19-27.

142. Wang C, Wang MW, Tashiro S, Onodera S, Ikejima T (2005) Effect of protein kinase $\mathrm{C}$ on human melanoma A375-S2 cell death induced by evodiamine. Yao Xue Xue Bao 40(11): 1033-1036.

143. Huang YC, Guh JH, Teng CM (2004) Induction of mitotic arrest and apoptosi by evodiamine in human leukemic T-lymphocytes. Life Sci 75(1): 35-49.

144. Takada Y, Kobayashi Y, Aggarwal B (2005) Evodiamine abolishes constitutive and inducible NF-kB activation by inhibiting IkB $\alpha$ kinase activation, thereby suppressing NF-kB regulated antiapoptotic and metastatic gene expression, up-regulating apoptosis and inhibiting invasion. J Biol Chem 280(17): 17203-17212.

145. Yang J, Wu LJ, Tashino S, Onodera S, Ikejima T (2008) Nitric oxyde activated by p38 and NF-kappaB facilitates apoptosis and cell cycle arrest under oxidative stress in evodiamine-treated human melanoma A375-S2 cells. Free Radic Res 42(1): 1-11.

146. Qiu C, Gao LN, Yan K, Cui YL, Zhang Y (2016) A promising antitumor activity of evodiamine incorporated in hydroxypropil- $\beta$-cyclodestrin: pro-apoptotic activity in human hepatoma HepG2 cells. Chem Cent 10: 46 .

147. Zhao LC, Li J, Liao K, Luo N, Shi QQ, et al. (2015) Evodiamine induces apoptosis and inhibits migration of HCT-116 human colorectal cancer cells. Int J Mol Sci 16(11): 27411-27421.

148. Liu X, Yang L, Bi Y, Wang LH, Huang H (2015) Effect of evodiamine in inducing apoptosis of gastric cancer SGC-7901 cells through mTOR signal pathway. Zhongguo Zhong Yao Za Zhi 40(16): 3262-3266.

149. Shen H, Zhao S, Xu Z, Wang LH, Huang H (2015) Evodiamine inhibits proliferation and induces apoptosis in gastric cancer cells. Oncol Lett 10(1): $367-371$

150. Khan M, Bi Y, Qazi JI, Fan L, Guo H. (2015) Evodiamine sensitizes U87 glioblastoma cells to TRAIL via the death receptor pathway. Mol Med Rep 11(1): 257-262.

151. Senthilkumar R, Bao An CH, Xiao Hui CA, Rong FU. (2014) Anticancer and multidrug-resistance reversing potential of traditional medicinal plants and their bioactive compounds in leukemia cell lines. Chinese journal of natural medicines 12(12): 881-894.

152. Hu CY, Wu HT, Su YC, Lin CH, Chang CJ, et al. (2017) Evodiamine exerts an anti-hepatocellular carcinoma activity through a WWOX-dependent pathway. Molecules 22(7): 1175.

153. Yang F, Shi L, Liang T, Ji L, Zhang G, et al. (2017) Anti-tumor effect of evodiamine by inducing Akt-mediated apoptosis in hepatocellular carcinoma. Biochem Biophys Res Commun 485(1): 54-61.

154. Ogasawara M, Suzuki H. (2004) Inhibition by evodiamine of hepatocyte growth factor-induced invasion and migration of tumor cells. Biological and Pharmaceutical Bulletin 27(4): 578-582.

155. Peng X, Zhang Q Zeng Y, Jin Li, Lixin Wang, et al. (2015) Evodiamine inhibits the migration and invasion of nasopharyngeal carcinoma cells in vitro via repressing MMP-2 expression. Cancer Chemother Pharmacol 76(6): 1173-1184.

156. Yuan XL, Zhang P, Liu XM, Du YM, Hou XD, et al. (2017) Cytological Assessments and Transcriptome Profiling Demonstrate that Evodiamine Inhibits Growth and Induces Apoptosis in a Renal Carcinoma Cell Line. Sci Rep 7(1): 12572.

157. Wu WS, Chien CC, Chen YC, Chiu WT (2016) Protein Kinase RNALike Endoplasmic Reticulum Kinase-Mediated Bcl-2 Protein Phosphorylation Contributes to Evodiamine-Induced Apoptosis of Human Renal Cell Carcinoma Cells. PLoS One 11(8): 0160484.

158. Shi CS, Li JM, Chin CC, Kuo YH, Lee YR, et al. (2017) Evodiamine Induces Cell Growth Arrest, Apoptosis and Suppresses Tumorigenesis in Human Urothelial Cell Carcinoma Cells. Anticancer Res 37(3): 11491159.

159. Wu WS, Chien CC, Liu KH, Chen YC, Chiu WT, et al. (2017) Evodiamine Prevents Glioma Growth, Induces Glioblastoma Cell Apoptosis and Cell Cycle Arrest through JNK Activation. Am J Chin Med 45(4): 879-899.

160. Wei L, Jin X, Cao Z, Li W (2016) Evodiamine induces extrinsic and intrinsic apoptosis of ovarian cancer cells via the mitogen-activated protein kinase/phosphatidylinositol-3-kinase/protein kinase B signaling pathways. J Tradit Chin Med 36(3): 353-359.

161. Chen TC, Chien CC, Wu MS, Chen YC (2016) Evodiamine from Evodia rutaecarpa induces apoptosis via activation of JNK and PERK in human ovarian cancer cells. Phytomedicine 23(1): 68-78.

162. Zhong ZF, Tan W, Wang SP, Wen An Qiang, Yi-Tao Wang (2015) Antiproliferative activity and cell cycle arrest induced by evodiamine on paclitaxel-sensitive and -resistant human ovarian cancer cells. Sci Rep 5: 16415.

163. Meng ZJ, Wu N, Liu Y, Shu KJ, Zou X, et al. (2015) Evodiamine inhibits the proliferation of human osteosarcoma cells by blocking PI3K/Akt signaling. Oncol Rep 34(3): 1388-1396.

164. Bai X, Meng H, Ma L, Guo A (2015) Inhibitory effects of evodiamine on human osteosarcoma cell proliferation and apoptosis. Oncol Lett $9(2)$ : 801-805.

165. Sachita K, Kim Y, Yu HJ, Cho SD, Lee JS (2015) In Vitro Assessment of the Anticancer Potential of Evodiamine in Human Oral Cancer Cell Lines. Phytother Res 29(8): 1145-1151.

166. Fang C, Zhang J, Qi D, Fan X, Luo J, et al. (2014) Evodiamine induces $\mathrm{G} 2 / \mathrm{M}$ arrest and apoptosis via mitochondrial and endoplasmic reticulum pathways in $\mathrm{H} 446$ and H1688 human small-cell lung cancer cells. PloS one 9(12): 115204.

167. Kan SF, Yu CH, Pu HF, Hsu JM, Chen MJ, et al. (2007) Anti-proliferative effects of evodiamine on human prostate cancer cell lines DU145 and PC3. Journal of cellular biochemistry 101(1): 44-56. 
168. Kan SF, Huang WJ, Lin LC, Wang PS (2004) Inhibitory effects of evodiamine on the growth of human prostate cancer cell line LNCaP. International journal of cancer 110(5): 641-651.

169. Huang DM, Guh JH, Huang YT, Chueh SC, Chiang PC et al. (2005) Induction of mitotic arrest and apoptosis in human prostate cancer pc-3 cells by evodiamine. The Journal of urology 173(1): 256-261.

170. Zhang T, Qu S, Shi Q, He D, Jin X (2014) Evodiamine induces apoptosis and enhances TRAIL-induced apoptosis in human bladder cancer cells through mTOR/S6K1-mediated downregulation of Mcl-1. International journal of molecular sciences 15(2): 3154-3171.

171. Zou Y, Qin X, Xiong H, Chen T, Wu H, et al. (2015) Apoptosis of human non-small-cell lung cancer A549 cells triggered by evodiamine through MTDH-dependent signaling pathway. Tumor Biology 36(7): 5187-5193.

172. Rasul A, Yu B, Zhong L, Khan M, Yang H, et al. (2012) Cytotoxic effect of evodiamine in SGC-7901 human gastric adenocarcinoma cells via simultaneous induction of apoptosis and autophagy. Oncology reports 27(5): 1481-1487.

173. Yang LI, Liu X, Wu D, Man Zhang, Guiping Ran, et al. (2014) Growth inhibition and induction of apoptosis in SGC-7901 human gastric cancer cells by evodiamine. Molecular medicine reports 9(4): 11471152.

174. Yue G, Wei J, Qian X, Lixia Yu, Zhengyun Zou, et al. (2013) Synergistic anticancer effects of polyphyllin I and evodiamine on freshly-removed human gastric tumors. PloS one 8(6): 65164.

175. Han S, Woo JK, Jung Y, Jeong D, Kang M, et al. (2016) Evodiamine selectively targets cancer stem-like cells through the p53-p21-Rb pathway. Biochemical Biophys Res Commun 469(4): 1153-1158.

176. Wang KL, Hsia SM, Yeh JY, Cheng SC, Wang PS, et al. (2013) Antiproliferative effects of evodiamine on human breast cancer cells. PloS one 8(6): 67297

177. Kobayashi Y, Nakano Y, Kizaki Mm Hoshikuma K, Yokoo Y, et al. (2001) Capsaicin-like anti-obese activities of evodiamine from fruits of Evodia rutaecarpa, a vanilloid receptor agonist. Planta Med 67(7): 628-633.

178. Chiou WF, Chou CJ, Shum AY, chen CF (1992) The vasorelaxant effect of evodiamine in rat isolated mesenteric arteries: mode of action. Eur ] Pharmacol 215(3): 277-283.
179. Lin CR, Amaya, F, Barrett L, Wang H, Takada J, et al. (2006) Prostaglandin E2 receptor EP4 contributes to inflammatory pain hypersensitivity. J Pharmacol Exp Ther 319(3): 1096-1103.

180. Wang T, Wang Y, Kontani, Y, Yoshinori Kobayashi, Yuzo Sato, et al (2008) Evodiamine improves diet-induced obesity in a uncoupling protein-1-independent manner: Involvement of antiadipogenic mechanism and extracellularly regulated kinase/mitogen-activated protein kinase signaling. Endocrinology 149(1): 358-366.

181. Lin H, Tsai SC, Chen JJ, Yu Chung Chiao, Shyi Wu Wang, et al. (1999) Effect of evodiamine on the secretion of testosterone in rat testicular interstitial cells. Metabolism 48(12): 1532-1535.

182. King CL, Kong YC, Wong NS (1980) Uterotonic effect of Evodia rutaecarpa alkaloids. J Nat Prod 43(5): 577-582.

183. Hung PH, Lin LC, Wang GJ, chen CF, wang PS, et al. (2001) Inhibitory effect of evodiamine on aldosterone release by Zona glomerulosa cells in male rats. Chin J Physiol 44(2): 53-57.

184. Rang WQ, Du YH, Hu CP, Ye F, Xu KP, et al. (2004) Protective effects of evodiamine on myocardial ischemia-reperfusion injury in rats. Planta Med 70(12): 1140-1143.

185. Yoshizumi M, Houchi H, Ishimura Y (1997) Effect of evodiamine on catecholamine secretion from bovine adrenal medulla. J Med Invest 44(2): 79-82.

186. Kobayashi Y (2003) The nociceptive and anti-nociceptive effects of evodiamine from fruits of Evodia rutaecarpa in mice. Planta Med 69: 425-428.

187. Chiou WF, Sung YJ, Liao JF, Andrew Yau Chik Shum, Chieh Fu Chen (1997) Inhibitory effect of dehydroevodiamine and evodiamine on nitric oxide production in cultured murine macrophages. J Nat Prod 60(7): 708-711.

188. Ko HC, Wang $\mathrm{YH}$, Liou KT, Chen CM, Chen $\mathrm{CH}$, et al. (2007) Antiinflammatory effects and mechanisms of the ethanol extract of Evodia rutaecarpa and its bioactive components on neutrophils and microglial cells. Eur J Pharmacol 555(3): 211-217.

189. Tsai TH, Lee TF, Chen CF (1995) Thermoregulatory effects of alkaloids isolated from $\mathrm{Wu}$-chu-yu in afebrile and febrile rats. Pharmacol Biochem Behav 50: 293-298.

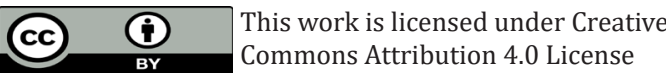

To Submit Your Article Click Here:

Submit Article

DOI: 10.32474/OAJOM.2018.01.000111

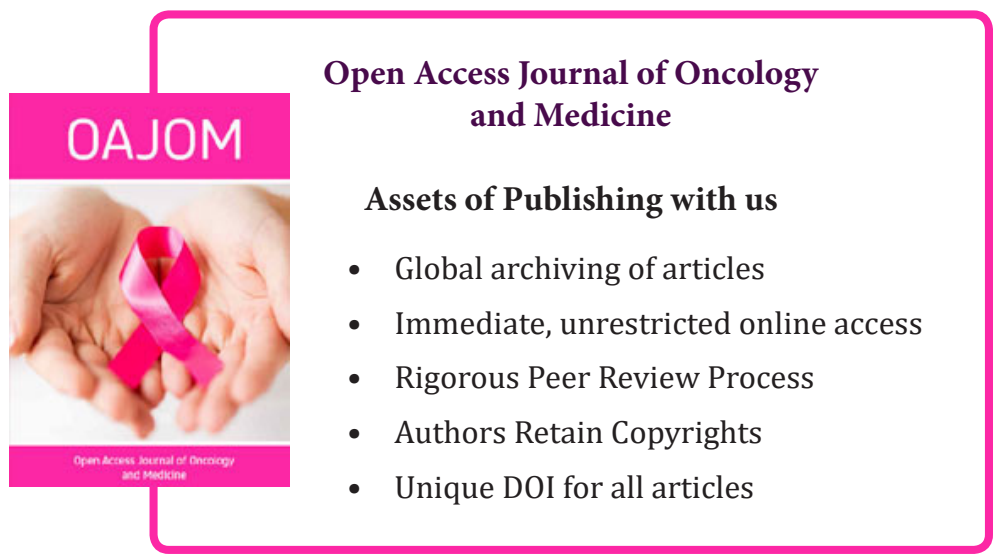

